\title{
BLICKDIAGNOSE
}

Bei einem 71-Jährigen

\section{Keine Haare, keine Nägel}

Ein 71-jähriger Patient wurde zur geplanten Anämiediagnostik aufgenommen. Die genaue körperliche Untersuchung zeigte eine komplette Alopezie und das Fehlen der meisten Finger- und Fußnägel.

— Bei der Anamneseerhebung berichtet der Patient über kompletten Haarverlust in der Zeit seit 1949 bis 1955 und einen kontinuierlichen Nagelverlust seit 1975.

Die Bedeutung eines fast völligen Verlustes der Fingerund Zehennägel ist nicht unerheblich: Feinmotorische Tätigkeiten der Hand sind erheblich erschwert, auch berichtete der Patient über eine partielle Gangunsicherheit. Diese Probleme sind gut nachvollziehbar, werden in der Literatur aber nur selten erwähnt.

Die Alopecia universalis ist ein seltenes Krankheitsbild. Die Ursachen sind nicht vollständig geklärt. Diese Alopezie wird als entzündliche, gewebespezifische Autoimmunerkrankung angesehen, sodass Therapieversuche mit Steroiden möglich sind.

Meistens kommt es zum Haarausfall im Kopfbereich (Alopecia totalis). Es können aber auch die Haare des gesamten Körpers und auch die Nägel betroffen sein (Alopecia universalis), nur selten kommt es zum vollständigen Nagelverlust.

Keywords: Alopecia totalis, Alopecia universalis, nail loss

- Robert Fijalkowski, Prof. Dr. med. Igor Alexander Harsch, Innere Medizin, Thüringen Kliniken Georgius Agricola, Rainweg 68, D-07318 Saalfeld/Saale

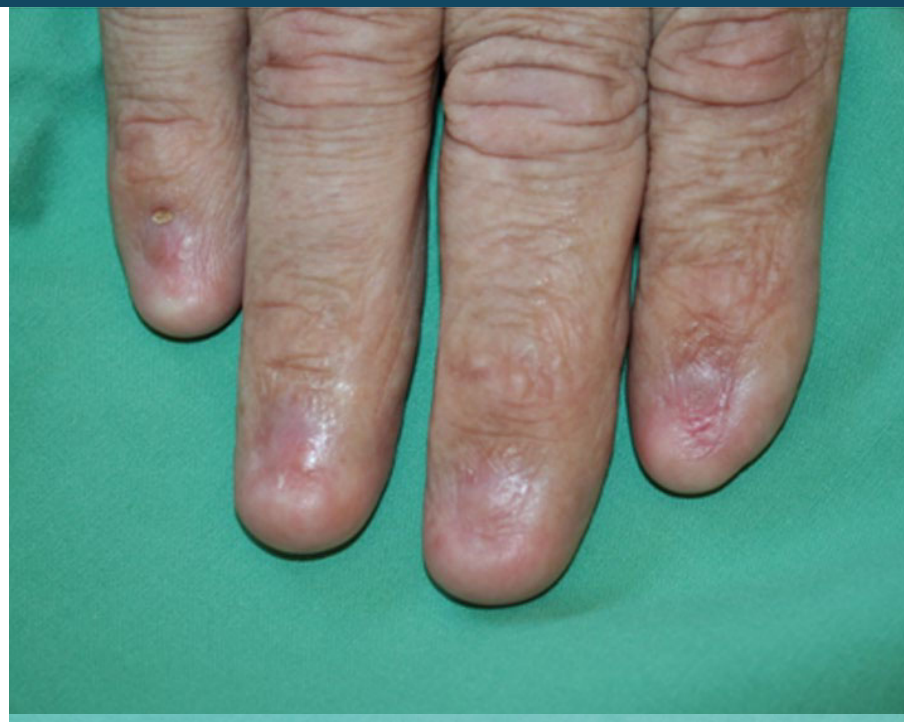

www.springermedizin.de

Weitere Blickdiagnosen finden Sie im Internet unter:

http://www.springermedizin.de/blickdiagnose 